\title{
Time to Refine How We Tweet?
}

read with great interest the article by Tomblinson et al ${ }^{1}$ about the role of hidden metrics for the evaluation of social media effectiveness. I think the topic is quite important while setting a social media strategy for a professional institution like the American Society of Neuroradiology (ASNR), which is spreading knowledge. Beyond the simple gaining of visibility, the presence on social media is meant to drive correct and high-level content, which is invariably stored on the Web sites of official journals and societies.

Luckily, we are not able to properly summarize an article in the short space available on Twitter, and the existence of a robust Web site where all content is available is crucial to preserve the knowledge.

A single post on social media lasts hours, then is forgotten, but we want to deliver science. As correctly highlighted by the authors, we have to think beyond Likes and Retweets because Tweets also are open to users not signed in to Twitter. Users could be interested in the topic of the Tweet and click on the link, with no interaction with the post itself.

http://dx.doi.org/10.3174/ajnr.A6457
I appreciated so much the awareness of the American Journal of Neuroradiology/ASNR in including in most of their tweets a link to their Web site. Moreover, quantifying which content is accessed and downloaded and how is important to discern the audience's satisfaction with a specific strategy.

As an example, in the European Society of Neuroradiology, last August, we proposed a review per day on social media channels, with highly interesting preliminary data about downloading of cited articles, regardless of whether they were open access. I am sure that paper can change the way some authors and educators think about health care social media posting, enhancing its use as a driver of content available on a specific (personal) Web site.

\section{REFERENCE}

1. Tomblinson P, Wadhwa V, Latimer E, et al. Publicly available metrics underestimate $A J N R$ Twitter impact and follower engagement. AJNR Am J Neuroradiol 2019;40:1994-97 CrossRef Medline

(1) G. D'Anna

Radiology Unit

Humanitas Mater Domini Castellanza (Varese), Italy 